\title{
Effect of the hydrodynamic conditions of electrolyte flow on critical states in electrochemical machining
}

\author{
Jerzy Sawicki $^{1 \mathrm{a}}$, Tomasz Paczkowski ${ }^{1}$ \\ ${ }^{1}$ University of Technology and Life Sciences in Bydgoszcz, Faculty of Mechanical Engineering
}

\begin{abstract}
The paper presents the results of experimental studies of electrochemical machining process oriented on occurring in the treatment critical states caused by electrolyte flow hydrodynamic conditions in the gap between electrodes. Material forming in electrochemical machining is carried out by anodic dissolution. In general in ECM process, the essence of the treatment is that the workpiece is the anode and the tool is the cathode. The space between the anode and cathode is filled by electrolyte. The current flow between the electrodes causes anodic dissolution process, resulting in the removal of material from the anode. Choosing in the process of electrochemical machining, respectively: anode and cathode material, electrolyte and processing parameters, such conditions can be created that enable a high process efficiency and smoothness of the surface. Inappropriate selection of machining parameters can cause the emergence of critical states in the ECM, which are mainly related to the flow of the electrolyte in the gap between electrodes. This work is an attempt to assess the occurring critical states in ECM on the example of machining of curved surfaces with any sort of outline and curved rotating surfaces.
\end{abstract}

\section{Introduction}

In electrochemical machining shaping the materials takes places through anode pulping. The essence of the treatment, in general, is that in the ECM process the workpiece (WP) is treated with the positive electrode (anode), and the tool electrode (TE) with the cathode (negative electrode). The space between the anode and cathode is filled with the agent that conducts electricity (electrolyte). The flow of the electric current between electrodes triggers the process of anode pulping, causing the removal of the material from the anode (workpiece) (Fig. 1).

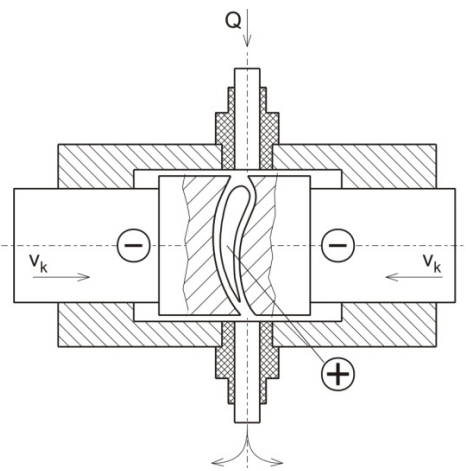

Figure 1. Example of electrochemical machining ,-,, working electrode (cathode), '+' blade (anode).

\footnotetext{
${ }^{\mathrm{a}}$ Corresponding author: sawik@utp.edu.pl
}

Adequately selecting in the electrochemical machining: the material of anode, cathode, electrolyte and machining parameters, one can create such conditions which facilitate producing a high efficiency of the process and surface smoothness.

\section{Critical states in the ECM process}

In the ECM process, the basic functional indicators, such as: efficiency, top layer state, as well as the dimension and profile accuracy, are increasing with an increase in the feed speed. The feed speed, however, is limited by the possibility of the occurrence of the critical state of the ECM process understood as the state described with a set of machining parameters in which the probability of the occurrence of electrical discharge and short circuit of electrodes increases rapidly. It is directly connected with the appearance, in the inter-electrode gap, of the phenomena referred to in literature as 'direct limitations', namely intensive evaporation or boiling on the surface of the electrode or electrolyte, cavitation, hydrodynamic instabilities, the occurrence of critical flow, the appearance, in the gap, of electric current conductive particles, the instabilities of the process (oscillations of electric current, the loss of the capacity for selfregulation, pulsations of electrolyte flow, thermokinetic instabilities of electrode processes [1]. 
In real ECM technological processes the knowledge of their courses is, unfortunately, limited. We are not able to prevent the occurrence of disturbances which are random in nature. An incomplete knowledge of changes which occur in the process of the machining (electrolyte properties, coefficient of machinability, electrode processes) makes it possible for the phenomena described above to occur during the ECM treatment. It means that there is a possibility of the occurrence of electrical discharge between electrodes and short circuit of electrodes. A direct cause of electric discharge is the loss of electrical conductivity through the electrolyte (breaking the cathode-electrolyte-anode system) as a result of non-conductive bubbles, vapour-gas layers. One can say that with an adequate intensity of electric field there occurs spark or arc discharge. The short-circuit found in the ECM process is simply mechanical contact of the cathode and anode. The spark discharge produced while maintaining the voltage, most often changes into arc discharge, which results in a high temperature causing damage (partial melting) of the surface of electrodes. When the gap thickness is small, the thrown particles of melted metal can lead to the metallic contact of electrodes, melting of electrodes and the damage of the machine tool. The intensity of damage in the process of ECM drilling increases with an increase in the density of current and decreasing gap thickness (when, obviously the reliability decreases). The critical value of the current intensity occurs directly before spark discharge. Usually the discharge interrupting the machining will appear in the final cross-section of the gap[1].

In most ECM cases, the occurrence of the critical state is connected with the so-called critical state in the two-phase zone in the-near-cathode region wedge (Fig. 2)[2].

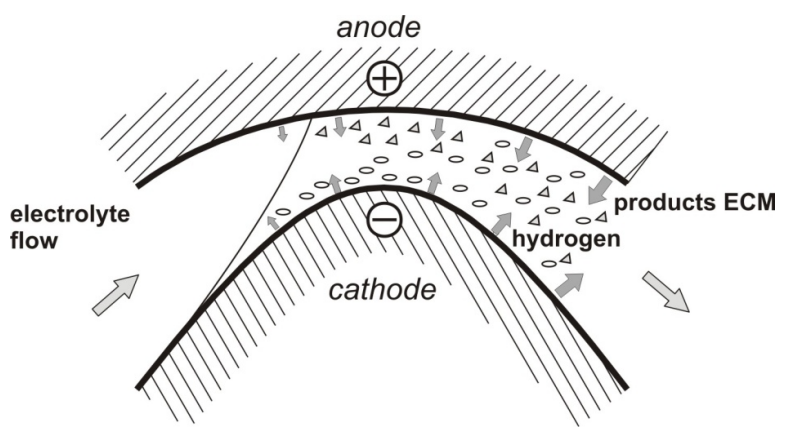

Figure 2. Zones of the flow of the electrolyte mixture in the inter-cathode gap.

When the flow velocity is low, the flow is laminar in nature, the critical state is connected with reaching the temperature of electrolyte boiling in the inter-electrode gap. Another parameter the occurrence of the critical state depends on is the gap thickness. There is boundary thickness below which the critical states are possible. Due to the fact that the knowledge of changes which occur in the machining process is not complete, the disturbances are random in nature, boundary thickness is usually experimentally determined [3].

\section{Experimental studies}

For the purpose of experimental studies, there has been designed and developed as well as made the test stand the body of which is given in Fig. 3 .

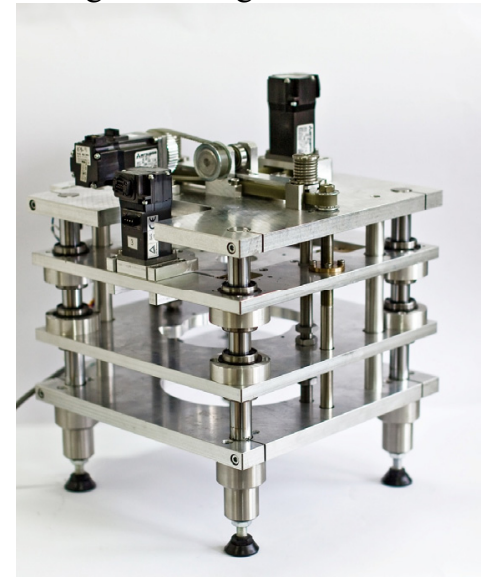

Figure 3. Body of the test stand.

The body is mounted with machining cells (Fig. 4) which allow for experimental tests of the electrochemical machining of shaped surfaces with curvilinear outline.

a)

b)
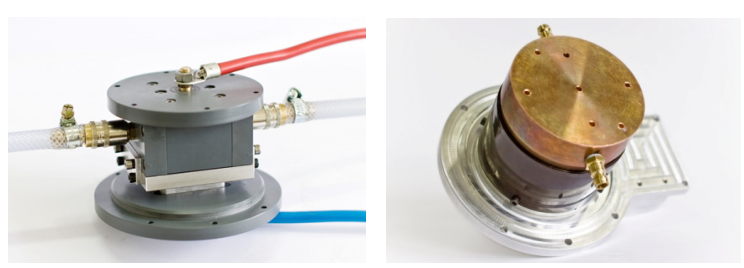

Figure 4. Machining cells: a) shaped surfaces, b) rotary surfaces.

The test stand equipped in such a way facilitates the performance of ECM experiments in the following variations (Table 1 ):

a) drilling with axisymmetric shaped electrode,

b) drilling with axisymmetric vibrating shaped electrode,

c) drilling with axisymmetric vibrating shaped electrode,

d) drilling with shaped electrode,

e) drilling with shaped electrode vibrating across the gap,

f) drilling with oscillatory-vibrating shaped electrode.

Table 1. ECM machining variations.

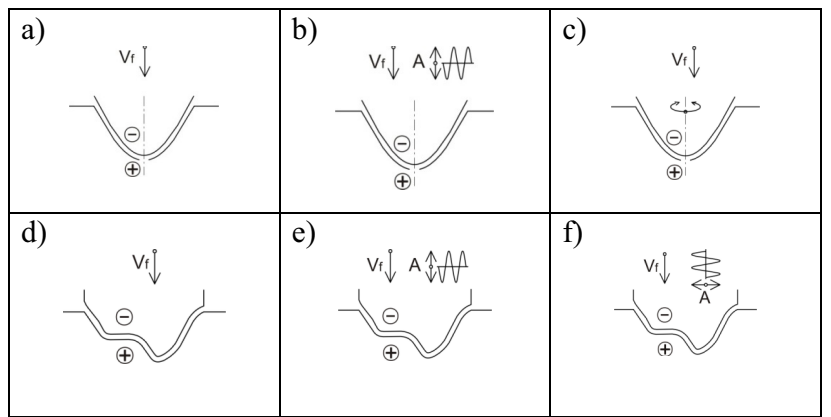


A detailed description of the test stand is presented in publications $[4,5]$.

The aim of the experimental studies has been the ECM machining of the surface with curvilinear outline, considering especially the critical states identified. The experimental verification was made for two ECM cases: - machining with rotary shaped electrode (Fig. 5a) rotating with the set rotational speed and well as vibrating with harmonic motion with the set amplitude and vibration frequency or vibration frequency according to the feed motion [6]. Such an ECM machining variant is a machining with a compound motion of the object machined (WP) (Fig. 5b).
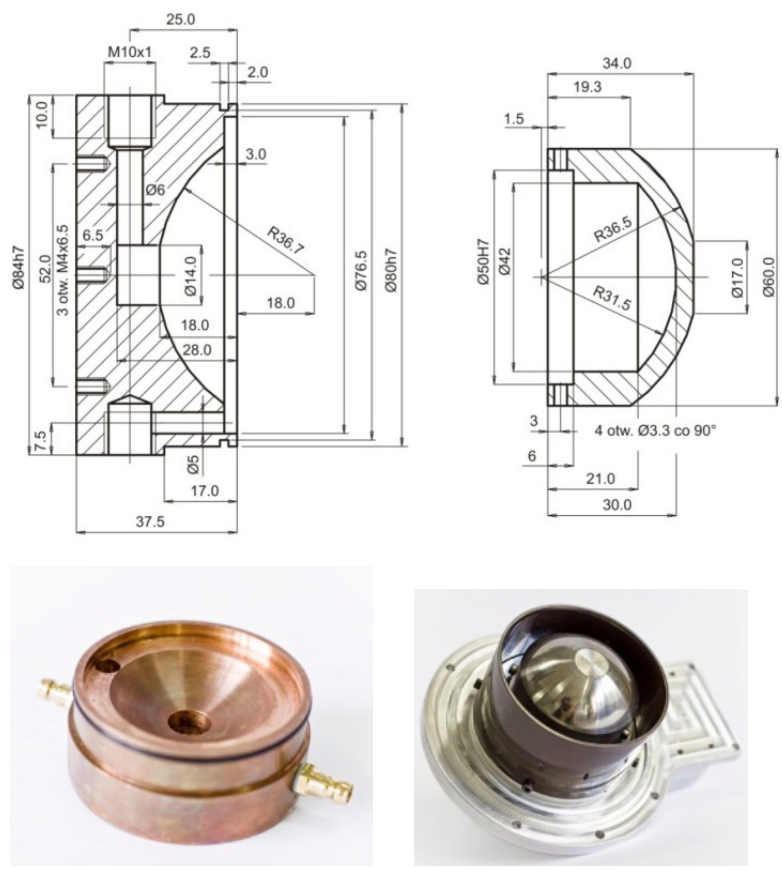

Figure 5. Geometric form of rotary electrodes.

The research assumed the following ECM rotary surfaces machining parameters:

\begin{tabular}{|l|l|}
\hline Inter-electrode voltage & $15 \mathrm{~V}$ \\
\hline Electrolyte type & $\mathrm{NaNO}_{3} 15 \%$ \\
\hline Electrolyte temperature & $293 \mathrm{~K}$ \\
\hline Powered with electrolyte & $Q=5 \mathrm{l} / \mathrm{min}, p_{z}=0.01 \mathrm{MPa}$ \\
\hline Initial thickness of the gap ME & $0.2 \mathrm{~mm}$ \\
\hline Velocity of feed motion $V_{f}$ & $1 \mathrm{~mm} \mathrm{m^{-1 }}$ \\
\hline Frequency & $60 \mathrm{~Hz}$ \\
\hline Amplitude $A$ & $0.1 \mathrm{~mm}$ \\
\hline $\begin{array}{l}\text { Machined Object Rotations } \\
\text { (WP) }\end{array}$ & 800.0 rotations $\mathrm{min}^{-1}$ \\
\hline Machining time & $60 \mathrm{~s}$ \\
\hline
\end{tabular}

The inter-electrode gap (IEG) was powered with constant flow rate $\mathrm{Q}$. The method of powering is given in Fig 6.

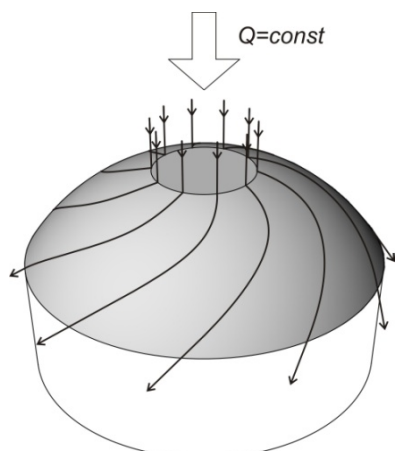

Figure 6. Diagram of the electrolyte flow along the interelectrode gap (IEG).

- machining with the shaped electrode with curvilinear outline (Fig. 7) with induced compound harmonic motion with set amplitudes $\mathrm{A}$ and vibration frequencies with simultaneously induced feed motion. Such compound kinematic motion was made for the electrodes the geometric form of which is given in Fig 7. The electrodes were mounted in the machining cell (Fig. 4a).

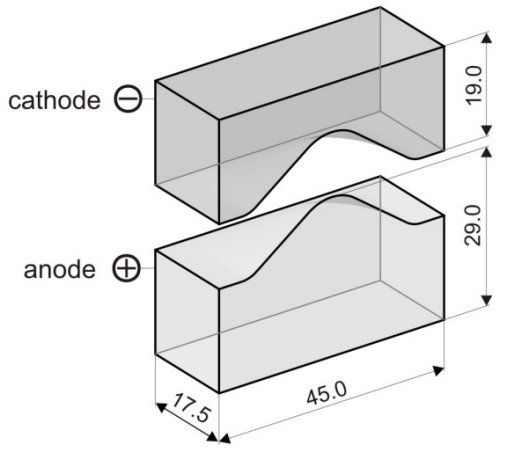

Figure 7. Geometric form of shaped electrodes with curvilinear outline.

The study assumed the following parameters of the ECM machining of the surface with curvilinear outline:

\begin{tabular}{|l|l|}
\hline Inter-electrode gap & $15 \mathrm{~V}$ \\
\hline Electrolyte type & $\mathrm{NaNO}_{3} \quad 15 \%$ \\
\hline Electrolyte temperature & $293 \mathrm{~K}$ \\
\hline Powered with electrolyte & $Q=3 \mathrm{l} / \mathrm{min}, p_{z}=0.01 \mathrm{MPa}$ \\
\hline Initial thickness of gap ME & $0.2 \mathrm{~mm}$ \\
\hline Longitudinal vibrations $f$ & $60 \mathrm{~Hz}$ \\
Amplitude $A$ & $0,1 \mathrm{~mm}$ \\
\hline Transverse vibration $f$ & $60 \mathrm{~Hz}$ \\
Amplitude $A$ & $0.05 \mathrm{~mm}$ \\
\hline \multicolumn{2}{|c|}{ Amplitudes of vibrations were shifted in phase by $90^{\circ}$} \\
\hline Velocity of feed motion & $V_{f}=1 \mathrm{~mm} \mathrm{m^{-1 }}$ \\
\hline Machining time & $60 \mathrm{~s}$ \\
\hline
\end{tabular}

The inter-electrode gap (IEG) was powered with constant flow rate $\mathrm{Q}$. The method of feeding is given in Fig 8. 


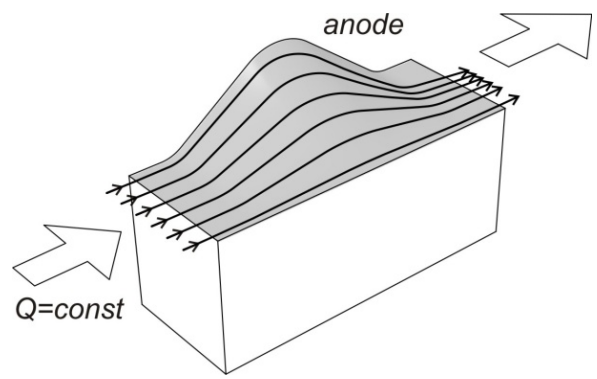

Figure 8. Digram of the flow along the inter-electrode gap IEG.

\section{Detailed conclusions}

Performed on the test stand (Fig. 3), experiments with ECM machining of the rotary surfaces (Fig. 5) and surfaces with curvilinear outline (Fig. 6) confirm the occurrence of critical states described in point 2 of this paper.

The flow in the inter-electrode gap can assume both laminar and turbulent flow. Considering the flow of electrolyte in the inter-electrode gap, one can differentiate in the flow area:

- flow with breakaway (electrolyte flow rate increases, pressure drops, most often to the pressure of boiling in a given temperature of electrolyte and cavitation appears),

- breakaway in the perpendicular plane (the so-called separation of the electrolyte sheet into respective stream most frequently resulting from inadequately selected inlet cross-section of the electrolyte),

- hydrodynamic-electrochemical resonance involving the hydrodynamics fields coupling with the processes of diffusion and pulping ECM.

\section{Surface of rotary object after ECM treatment}

Fig. 10 presents a specimen where on the inlet to the inter-electrode gap (IEG) there were observed defects caused by cavitation. The phenomenon is connected with e.g. unevenness of hydrodynamic conditions in that area. In the region of the electrolyte inlet to the inter-electrode gap (IEG) there occurs a rapid change in pressure resulting from the appearance, on the inlet, of ring curtain with the area making throttle elements. The trace, which is a clear surface defect, depends on flow velocity and pressure. Interestingly, the surface defects, given in Fig.8 caused by cavitation are intensified by the process of electrochemical pulping deformed by hydrodynamic phenomena.

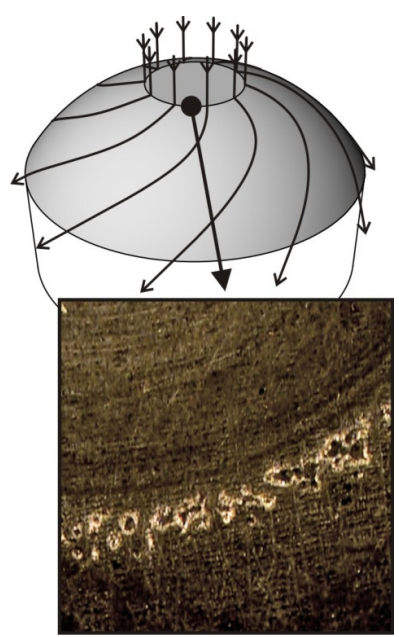

Figure 9. Image of the surface of the rotated object (WP) after the ECM treatment.

\section{Surface of the object with curvilinear outline}

Fig 9 demonstrates the defect of the surface machined just behind the inlet to the inter-electrode gap (IEG). In the photo you can see visible effects of cavitation identified from characteristic pitting; a result of inadequately selected cross-sections of inlets of the electrolyte to the inter-electrode gap as well as flow parameters.

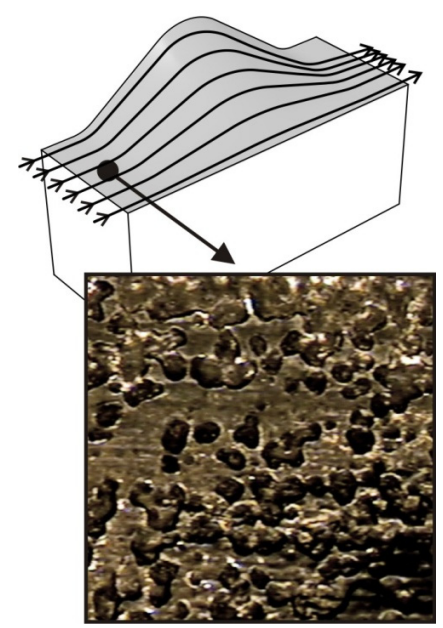

Figure 10. Image of the surface of the object with curvilinear outline after the ECM treatment.

Fig. 11 presents the image of the surface about $2 / 3$ of the gap length away where a clear surface defect was recorded. It is an area of hydrogen which appears on the cathode. Just at the cathode there is created the two-phase flow zone (electrolyte + gas bubbles). The emergence of the gas phase definitely deteriorates the technological characteristics of the process due to changes in the properties of the medium, especially a decrease in electrolytic conductivity. One shall stress that the real concentration of gas in the two-phase zone is not definitely defined. The maximum concentration of gas ranges from 0.3 to 0.5 and further growth of gas concentration leads to an increase in temperature in the vicinity of the cathode causing surface boiling. This kind 
of phenomena results in the flash-over, short circuit and even stopping of machining.

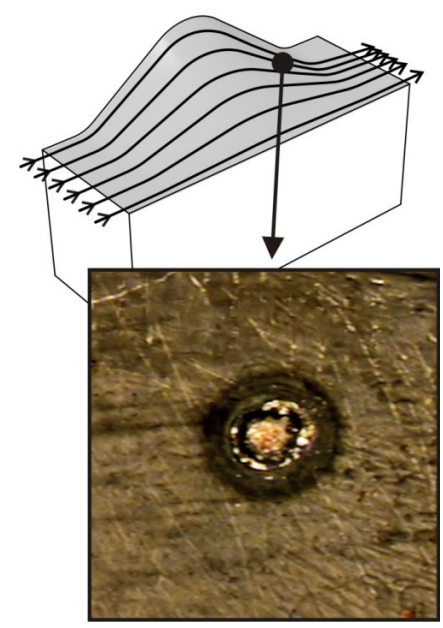

Figure 11. Image of the surface of the object with curvilinear gap after the ECM treatment.

Fig. 12 presents the surface of the treated object near the outlet from the inter-electrode gap.

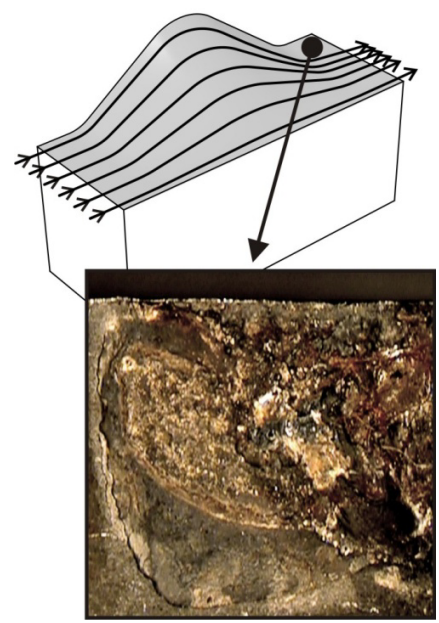

Figure 12. Image of the surface of the object with curvilinear outline after the ECM machining.

The real conditions of the ECM machining cause the production of gases and products of anode pulping, thus causing additional process disturbances. The ions of metal of the anode due to chemical reactions result in the formation, in the electrolyte solution, of insoluble hydroxides which form the gelatinous suspension (the so called silt). The particles of the suspension coagulate, forming greater clusters with extended area. An increase in the concentration of silt results in slight changes in electrolytic conductivity of electrolyte, an increase in viscosity, decrease in the flow velocity, a decrease in thermal conductivity and thus an increase in the temperature of electrolyte and electrodes. The excessively high decrease in velocity of the flow of electrolyte results in the deposition of slim on the surface of the electrodes. It is unfavourable, especially when machining gaps are long. There is a danger of stopping the flow of the electrolyte. Coagulating particles of silt can create conductive or non-conductive, the so-called, bridges being the cause of local short circuits of electrodes and the formation of electrical arc.

\section{Recapitulations}

This paper concerns the preliminary studies of the effect of hydrodynamic conditions of electrolyte flow on critical states in electrochemical machining. The studies of the machining of rotary surfaces and surfaces with curvilinear outline show that for set machining parameters in both cases one can observe some defects of machined surfaces characteristic for the so-called critical states which occur in the ECM machining.

The preliminary studies make it possible to select experimentally the parameters of the ECM process. The selection of those parameters is especially difficult in the case of the machining of complex surfaces and about creating curvilinear outline. From practise and studies it is known that the ECM process of such surfaces is performed in the transition range of $2300<\mathrm{Re}<50000$ and so the flow must be, at the same time, both laminar and turbulent in various areas of the machining zone. A change in the nature of the flow from laminar into turbulent causes changes in the electrolyte flow velocity and, as a result, often an unfavourable increase in temperature of the medium leading to electrical discharge. The nature of curvilinear surfaces also often leads to the separation of electrolyte into respective streams and, as a result, to its inhomogeneity, a loss of electrical conductivity and the formation of electric arc. Flow disturbances leading to critical states can be also due to an inadequate design of the inlet of electrolyte, which most often results in the occurrence of cavitation there.

One of the factors affecting the machining stability is introducing the vibration of the working electrode. Such vibration leads to stopping the pre-short-circuit processes and, at the same time, makes a periodic rinsing of the machining zone possible.

In the present research for both machining cases a correction was made in terms of the method of feeding the electrolyte to the inter-electrode gap as well as the values of flow rate on the inlet.

\section{References}

1. K. Łubkowski, Stany krytyczne w obróbce elektrochemicznej, Prace Naukowe, Mechanika, z.163, Oficyna Wydawnicza PW, (1996)

2. J. Kozak, Kształtowanie powierzchni obróbka elektrochemiczna bezstykowa (ECM) Prace Naukowe Mechanika z.41, Oficyna Wydawnicza PW, (1976)

3. T. Paczkowski, J. Zdrojewski, J. of POLISH CIMAC, Vol. 6 No 3, (2011)

4. T. Paczkowski, PN SNOE, nr 14, PAN KBM SPT, (2008)

5. T. Paczkowski, Świat Obrabiarek nr 1-2 (2010)

6. J. Sawicki, Analiza $i$ modelowanie obróbki elektrochemicznej krzywoliniowych powierzchni obrotowych, Rozprawy 164, Wydawnictwa Uczelniane UTP, (2014) 